East African Medical Journal Vol. 81 No. 7 July 2004

SALMONELLAE CARRIER STATUS OF FOOD VENDORS IN KUMASI, GHANA

P. K. Feglo, BSc, MSc, Department of Clinical Microbiology, School of Medical Sciences, KNUST, E. H. Frimpong, BSc, MBChB., Dip Bact (Manc), Food Research Institute, CSIR, Accra, Ghana and Department of Clinical Microbiology, School of Medical Sciences, KNUST, Kumasi, Ghana and M. Essel-Ahun, BSc, MBChB, MPH, Ministry of Health, Accra, Ghana

Request for reprints to: Prof. E. H. Frimpong, Department of Clinical Microbiology, School of Medical Sciences, KNUST, Kumasi, Ghana

\title{
SALMONELLAE CARRIER STATUS OF FOOD VENDORS IN KUMASI, GHANA
}

\author{
P. K. FEGLO, E. H. FRIMPONG and M. ESSEL-AHUN
}

\begin{abstract}
Objective: To determine the prevalence of chronic typhoidal salmonellae amongst food vendors in Kumasi Ghana.

Design: A prospective study.

Setting: Sitting and itinerant food vendors in Kumasi.

Methods: Screening of 258 (230 females of 28 males) healthy food vendors for Salmonella typhi, and S. paratyphi $\mathrm{A}, \mathrm{B}$, and $\mathrm{C}$, using stool culture, the widal test, and standard microbiological identification methods.

Main outcome measures: Prevalence of chronic typhoidal Salmonellae carriers among food vendors in Kumasi.

Results: Typhoidal Salmonellae were isolated from six people, giving a carriage rate of $2.3 \%$. Three of the Salmonellae isolated were $S$. typhi, and they had significant Widal agglutinin titres of $\geq 1 / 160$ and $\geq 1 / 320$ for 0 and $H$ antigens, respectively. The other three were non-typhoidal Salmonellae. The three had S. typhi and the other three had titres of 1/80 or less for both 0 and $H$ antigens, respectively. We have discussed the implications of this high carriage rate, and we have suggested the inclusion of screening for Salmonellae of the regular health screening exercise undertaken by food handlers to detect and monitor chronic carriers in the food industry, to help control salmonella diseases in the community.

Conclusion: From our study, food handlers consitute a significant risk in the spread of enteric fever in Kumasi. We therefore, suggest the inclusion of screening for Salmonellae in the regular obligatory six-monthly examination required of food handlers and to monitor those found to be infected.
\end{abstract}

\section{INTRODUCTION}

Globally, typhoid and paratyphoid fevers account for 12.5 million cases annually, and typhoid fever continues to present considerable health problems in many developing countries(1,2). Enteric fever is endemic in Ghana and is a major health problem(3).

Of the over 2,200 different types known, only Salmonella typhi, S. paratyphi A, B and C, traditionally cause invasive enteric fever. These are the typhoidal Salmonellae. The other Salmonellae only cause food poisoning and it is only recently some non-typhoidal Salmonellae have been shown to invade the blood stream $(2,4,5)$.

Salmonella's infection is acquired from eating and drinking of infected foods and water(2,5). Salmonellae are not fastidious and thrive in many foods and drinks; both freshly prepared and stored food, and both hot and cold $(2,5)$. The source of the infection is faeces or urine of infected persons(2,5). Healthy chronic carriers, especially food handlers, are very important in the transmission; particularly in places with low environmental sanitation where many people eat out(2,5-7), as is the case in Kumasi.
Mensah et al. in Accra have reported a prevalence of $3.2 \%$ in a study involving 176 food vendors(8). Kumasi, the study area, like many urban places in Ghana, still has a significant problem in environmental sanitation. Many homes do not have their own toilet and there are inadequate public toilets. Many of these public toilets are of the privy type, with no water available for hand washing. Many food sellers and their customers use such toilets. Because of the importance of chronic typhoidal-Salmonellae carrier food handlers in the chain of infection, screening for Salmonellae among food handlers is important(2,5-7), though this practice has been deemed not cost efficient by WHO(9). However, the screening for Salmonellae is not one of the usual routine tests required of food sellers in Kumasi hence the risk posed by food handlers here, is not known.

We therefore decided to screen food handlers in Kumasi to determine whether they constitute a major source of dissemination of Salmonellae, and if so, to suggest the inclusion of Salmonellae screening in the routine health screening, and to monitor those found to be infected. 


\section{MATERIALS AND METHODS}

The study was undertaken at the Microbiology laboratory, School of Medical Sciences (SMS), KNUST, Kumasi, Ghana, from February to April 1995. It was approved by the SMS Ethical Committe and informed consent were granted by the subjects.

Study area: Kumasi the capital of Ashanti region of Ghana population (Approx. 700,000) is in the tropical forest. The inhabitants are farmers, merchants and petty traders, artisans, government and company workers. The city has good water supply and drainage system, but there are environmental sanitation problems from poor solid waste disposal.

Subjects: Within a period of three months, 258 healthy food handlers aged 12 to 65 years, were screened using stool culture and the widal test. The subjects were first 258 itinerant and seated food vendors (covering all major parts of the city) in the Kumasi who satisfied the inclusion criteria and agreed to participate in the study. Those with fever, diarrhoea headache, constipation or abdominal pains-symptoms of active enteric disease and those who refused consent were excluded.

In the calculation of sample size an assumption of two Salmonella isolates per 100 specimens, based on previous studies elsewhere at a power of $95 \%$ was made. This formula determined that a sample size of 200 or more was representative.
Stool samples were collected into clean monowax containers and transported in an ice box to the laboratory. All samples were emulsified with saline and plated directly on Deoxycholate Citrate Agar (DCA), the primary plate, and then into enrichment medium Selenite $F$ broth(SFB) and incubated at $37^{\circ} \mathrm{C}$ overnight. Salmonellae were isolated and identified using standard biochemical and serological methods (10). Due to cost constraint, Salmonellae species were not serotyped.

Widal test: Widal tests were performed by the slide test, on serum dilution of $1 / 20$ and $1 / 80$, then by the standard tube dilution method, for samples agglutination at both dilution, using the Febrile Antigen test kit supplied by Plasmatec, Folkestone, Kent, UK. Samples were screened for anti-0somatic and anti-H-flagella antigens of Salmonella typhi and Salmonella paratyphi A, B, and C.

\section{RESULTS}

Of the 258 food handlers screened, Salmonellae were isolated from six people; giving a Salmonellae carriage rate of $2.3 \%$. The six were all women. Three of the six Salmonellae isolated, were S. typhi and the other three, non-typhoidal Salmonellae species. The full agglutinin titres are shown in Tables 1 and Table 2 and for all the food handlers respectively.

Table 1

Isolates from six positive stool cultures and their corresponding reciprocal Widal titres

\begin{tabular}{|c|c|c|c|c|c|c|c|c|}
\hline \multirow[t]{2}{*}{ Isolates from Stool } & \multicolumn{5}{|c|}{$\begin{array}{l}\text { Widal antigens } \\
\text { S. Paratyphi }\end{array}$} & \multirow[b]{2}{*}{$\begin{array}{l}\mathrm{B} \\
\mathrm{H}\end{array}$} & & \multirow[b]{2}{*}{$\begin{array}{l}\mathrm{C} \\
\mathrm{H}\end{array}$} \\
\hline & $\mathrm{O}$ & $\mathrm{H}$ & $\begin{array}{l}\mathrm{A} \\
\mathrm{O}\end{array}$ & $\mathrm{H}$ & $\mathrm{O}$ & & $\mathrm{O}$ & \\
\hline 1. Salmonella typhi & 80 & 320 & & 40 & & & & \\
\hline 2. Salmonella typhi & 160 & 640 & & & & & & \\
\hline 3. Salmonella species & 160 & 320 & 20 & 160 & & & & 80 \\
\hline 4. Salmonella species & 80 & & & & & & & \\
\hline 5. Salmonella species & & 80 & & & 80 & 160 & & 40 \\
\hline 6. Salmonella species & & & 80 & & & & & \\
\hline
\end{tabular}

Table 2

Widal agglutinins (' $O$ ' and ' $H$ ') test results among 307 food handlers in Kumasi Ashanti Ghana, in relation to the causal agents of enteric fevers

\begin{tabular}{|c|c|c|c|c|c|c|c|c|c|c|c|c|c|c|}
\hline Antigen Type & $<1 / 20$ & $\%$ & $<1 / 20$ & $\%$ & $1 / 40$ & $\%$ & $1 / 80$ & $\%$ & $1 / 60$ & $\%$ & $1 / 320$ & $\%$ & $1 / 640$ & $\%$ \\
\hline Salmonella $\mathrm{O}$ & 214 & 9.7 & 53 & 17.3 & 23 & 7.5 & 12 & 4.6 & 3 & 1.0 & 0 & 0 & 0 & 0 \\
\hline Typhi $\quad \mathrm{H}$ & 149 & 48.5 & 27 & 8.8 & 52 & 16.9 & 48 & 15.6 & 32 & 10.4 & 7 & 2.3 & 1 & 0.3 \\
\hline Salmonella $\mathrm{O}$ & 283 & 92.2 & 17 & 5.5 & 5 & 1.6 & 1 & 0.3 & 1 & 0.3 & 0 & 0 & 0 & 0 \\
\hline Paratyphi AH & 255 & 83.1 & 15 & 4.9 & 21 & 6.8 & 15 & 4.9 & 1 & 0.3 & 0 & 0 & 0 & 0 \\
\hline Salmonella O & 277 & 90.2 & 13 & 4.2 & 7 & 2.3 & 10 & 3.3 & 0 & 0 & 0 & 0 & 0 & 0 \\
\hline Paratyphi BH & 262 & 85.3 & 8 & 2.6 & 4 & 1.3 & 29 & 9.4 & 4 & 1.3 & 0 & 0 & 0 & 0 \\
\hline Salmonella O & 283 & 92.2 & 11 & 3.6 & 8 & 2.6 & 5 & 1.6 & 0 & 0 & 0 & 0 & 0 & 0 \\
\hline Paratyphi $\mathrm{CH}$ & 267 & 86.9 & 14 & 4.6 & 12 & 3.9 & 8 & 2.6 & 6 & 1.9 & 0 & 0 & 0 & 0 \\
\hline
\end{tabular}

The Widal test result for the three S. typhi carriers were: 0:1/80, H:1/320 0:1/160, H:1/640 0:1/160, H:1/320 respectively, for the 0 -somatic and H-flagella antigens. The other three, with non-typhoidal salmonellae had titres of 1/80 or lower, for both the 0 and $\mathrm{H}$ antigens 


\section{DISCUSSION}

We have attempted by this study to establish the Salmonellae carriage among a population of food handlers in Kumasi, Ghana. A rate of $2.3 \%$ was determined. This high rate contrasts with the rate of $0.13 \%$ quoted for the developed world(4), and is interestingly similar to the rate of $3.2 \%$ of Mensah et al. in Accra(8), the 2\% in Malaysia in 1983 given by Pang and Puthucheary(11) and interestingly close to the $3.6 \%$ given by Welch et al(12) in 1925, almost a century ago for the United States. Yet others; Gelosa et al. in Italy(13), and Yamada et al. in Tokyo(14) have reported $1.68 \%$ and $0.7 \%$ respectively.

The former method of using the Vi antibody detection test has been largely discarded in favour of using stool cultures and the Widal test, despite their limitation for the detection of carriers(5). The method used is therefore adequate.

The nature of the subjects i.e itinerant vendors, make it difficult taking more than one specimen. However, it is known that Salmonellae are transmitted intermittently in the stool of chronic carrier and this makes routine screening not particularly cost effective $(5,8)$. Notwithstanding the limitation, the value obtained is thus a reflection in part, of the total expected. Thus the figure could be higher.

The Widal test results of three out of the six food handlers with positive stool cultures are significant for enteric infection according to our recently determined diagnostic Widal test titres for Kumasi based on the residual titres of the healthy population in Kumasi(15). In the publication, Frimpong et al. (15) suggested for adoption for diagnosis of enteric fever, Widal titres of $\geq 1 / 160$ and $\geq 1 / 320$ for anti-0 and anti -H-respectively. Significantly, those food handlers with positive stool cultures for non-typhoidal Salmonellae had insignificant titres.

A report from Spain(16) where one chronic carrier, a casual food handler, was shown to have infected 70 others, still highlights the continued importance of chronic Salmonellae carriers especially food handlers in the spread of the disease a fact that has been long established $(2,5,8,13,14)$.

With the increase in tourism and commerce, mass catering has become very important; considering therefore the problem posed by chronic carriers, greater attention must be paid to the health of people engaged in the food industry.

The preponderance of women in the study, giving a ratio of women to men at 1:10, reflects the dominant position of women in the food industry. This was also seen in the Accra study(8). The study shows women to be more likely to become chronic carriers than men(5). However, the small number of organisms isolated does not permit any reliable deductions on the carrier status of both sexes.
Of concern too, are school children, as many do not carry lunch boxes and eat from road side food sellers; children are more susceptible to Salmonellae infection, and the disease tend to be more severe $(2,5)$.

Although the city has adequate water supply, many food handlers and consumers, in the course of the day, who use the public toilets are unlikely to wash their hands after using the toilet due to the absence of water at these public toilets.

Again, though chlorinated tap water kill Salmonellae(17), many people living in city slums and shanty towns are without tap-water and are at a risk of infection. And as enteric fever is known to be endemic in places of low personal hygiene and environmental sanitation $(2,5,8)$ a situation that pertains in Kumasi like many African cities, steps must be taken to rectify this situation.

However, given the time and money required to improve environmental sanitation, and increase the accessibility of water, the most rewarding option is the education and the regular screening of food handlers with a view to following up those found infected and getting them cured. We therefore conclude from our study that, food handlers constitute a significant risk in the spread of enteric fever in Kumasi and therefore suggest the inclusion of Salmonellae screening in the regular health profile examination that is required of food handlers and to monitor those found to be infected.

\section{ACKNOWLEDGEMENTS}

To Prof. Dr. Pat A-K. Addy, formerly Head, Department of Clinical Microbiology, School of Medical Sciences for advice and Mr. C.K. Akuako and the staff of the Food Inspectorate Division, Kumasi Metropolitan Authority, for help in the recruitment and screening of the food handlers.

\section{REFERENCES}

1. Edelman, R. and Levine, M.M. Summary of an international workshop on typhoid fever. Rev Inf. Dis. 1986; 8:329-349.

2. Christie, A.B. Infectious diseases: Epidemiology and clinical practice. 4th edn. Edinburgh: Churchill Livingstone. 100-164.

3. Archampong, E.Q. Typhoid ideal perforations: why such mortalities? Brit. J. Surg. 1976; 63:317-321.

4. Falkow, S. and Mekalanos, J. The enteric bacilli and vibrios. In: Davis B.D., Dulbecco R., Eisen H.N., Ginsberg H.S. (eds.), Microbiology, 4th edn. Philadelphia: Lippincott Co. 1990; 561-579.

5. Wilson, G.S., Miles, A.A. Topley, and Wilson's Principles of Bacteriology, Virology and Immunity. 6th edn. London: Edward Arnold, 1975: 2005-2039.

6. Itotia, J.N., Cruickshank, R. and Refai, M. Bacteriological investigations of feaces from diarrhoeal cases and apparently healthy persons with reference to food handlers in Kenya. East Afr. Med. J. 1978; 55:366-372.

7. Adungo, N.I. and Githeko, A.K. The possible impact of food handlers in the transmission of gastro-intestinal parasites in an urban community. Current research on gastro- 
intestinal tract and associated organs in the African environment. Proceedings of the fifth Annual Medical Scientific Conference, of the Kenya Medical Association, Nairobi, Kenya. 1984; 51-54.

8. Mensah, P. Owusu-Darko, K. Yeboah-Manu, D. et al. The role of street food vendors in the transmission of enteric pathogens in Accra. Ghana Med. J. 33:19-29.

9. W.H.O Technical Report Series Number 785. Health surveillance and management procedures for food handling personnel. Switzerland: WHO. 1989.

10. Cowan, S.T. Cowan and Steel's Manual for identification of medical bacteria. 2nd edn. Cambridge University Press, 1978: 113-114.

11. Pang, T. and Puthucheary, S.D. Significance value of the Widal test in the diagnosis of typhoid fever in an endemic area. J. Clin Pathol. 1983; 36: 471-475.

12. Welch, S.W., Dehler, S.A., Haens, L.C., JAMA. 1925: 85; 1036. quoted from Topley and Wilson (5).
13. Gelosa, L. Antibiotic sensitivity of Salmonella strains from food-handlers in the period 1980-1988 in Italy. J. Chemother. 1991; 1(supp. 3):80-83.

14. Yamada, S., Matushita, S. and Kudoh, Y. Recovery and its evaluation of Shigella bacilli or Salmonella from healthy food handlers in Tokyo (1961-1997). Kansenshogaku Zasshi 1999; 73:758-765.

15. Frimpong, E.H., Feglo, P., Essel-Ahun, M. and Addy, P.A.K. Detelmination of diagnostic Widal titres in Kumasi Ghana. West Afr. J. Med. 1999; 19:34-38.

16. Xercavins, M., Llovet, T., Navarro, F. et al. Epidemiology of an unusual outbreak of typhoid fever in Terrasa, Spain. Clin. Inf. Dis. 1997; 24:506-510.

17. Robinson, D. Epidemiology and community control of diseases in warm climate countries, 2nd edn. Toronto. Churchill Livingstone. 1985; 296-303. 